\title{
The Effect of the Gender and Culture of the IELTS Examiner on the Examinees' Performance on the IELTS Speaking Test in the UAE Context
}

https://doi.org/10.33806/ijaes2000.19.1.2

\author{
Abdel Rahman Mitib Altakhaineh \\ Al Ain University of Science and Technology \\ Khawlah M. AL-Tkhayneh \\ Al Ain University of Science and Technology \\ Hanan N. Rahrouh \\ Al Ain University of Science and Technology
}

\begin{abstract}
This study examined the effect of the gender and culture of the IELTS examiner on the performance of Arab examinees on the IELTS speaking test. It relied on Communication Accommodation Theory to account for the linguistic behaviour of the examinees in reaction to the gender and the culture of the IELTS examiner. Through interviewing 15 female and 15 male IELTS examinees in Al Ain, the UAE and conducting focus group interviews with 10 IELTS teachers, the study showed that the two independent variables, i.e. the gender and culture of the IELTS examiners had different impacts on the examinees' performance on the IELTS speaking test. The results demonstrated that the gender of the IELTS examiner affected the performance of the Arab examinees in terms of preference. It also showed that the examiners' culture influenced the answers provided by the examinees who may not have been aware of certain cultural aspects related to the questions asked in the IELTS speaking test and vice versa. With respect to communication accommodation, the IELTS examinees' answers demonstrated a divergence tendency rather than a convergence one, reflecting a desire to establish social distance with the interlocutor, which may exhibit their strong feelings about their identity.
\end{abstract}

Keywords: Arab examinees, communication accommodation theory, culture, gender, IELTS speaking test, UAE

\section{Introduction}

In the context of learning a foreign or a second language, four skills are usually tested, namely, reading, listening, writing and speaking. These four skills, also known as the four skills of language learning, can be defined as a set of capabilities which allow L2 learners to comprehend and produce spoken language, enabling them to communicate effectively with native speakers of the target language. From the point of view of the examiner, speaking is regarded as a productive skill due to its communicative nature which can only be measured in live interaction. This skill also requires individuals to use their vocal tract and their brains to be able to produce language through sound correctly (IELTSBritish Council 2017). The primary objective of developing speaking skill is to 
communicate successfully in the target language, acquiring both comprehensive as well as productive skills (see Zibin 2016). Due to its vital importance in promoting communicative efficiency, the speaking test has been regarded as an integral part of language proficiency tests such as the TOEFL (Test of English as a Foreign Language) and the IELTS (International English Language Testing System). Individuals who know a particular language are referred to as speakers of that language; this can be attributed to the fact that this skill entails the ability to communicate successfully with others, taking into account their cultural background. Thus, we find that many studies have investigated the impact of culture on the linguistic behaviour of individuals (e.g. Tarone and Yule 1987; Ji et al. 2004; Sun 2007). The argument in such studies was based on the idea that a target language can never exist in isolation of its culture. Therefore, several researchers (e.g. Vernier et al. 2008:278) argued that teaching the target culture can be considered a fifth skill for L2 learners, as it enhances their whole learning experience. In addition to culture, the gender of the interlocutor can also have an impact on the linguistic behaviour of individuals (see for example Basow 1995), especially those who belong to conservative cultures (see Byram 1994). Based on the above, it can be argued that the gender and the culture of the interlocutor can have an impact on the linguistic behaviour of individuals. Few studies have been conducted in the relevant literature to investigate the effect of variables, such as the culture and the gender of the IELTS examiner on the performance of IELTS examinees on the speaking test (e.g. O'Loughlin 2000, 2002; Khan 2006; Roshan 2013; among others). This study aims to bridge this gap; in particular, adopting an accommodation theoretical framework (Giles 1984, 2007), it aims to investigate the ways in which the gender and the culture of the IELTS examiner influence the performance of Arab IELTS examinees on the speaking test in the United Arab Emirates (UAE) context, adopting qualitative data elicitation tools. Conducting this study can provide insights into one of the most used language proficiency tests (IELTS) around the globe and into the methods of assessment used in the speaking component in that test. Exploring the views and experiences of the IELTS examinees belonging to different cultures and shedding light on the difficulties, related to the gender and culture of the IELTS examiner, which they may face may provide an incentive for the British Council to reconsider some of its techniques and material, resulting in a revised version of the test and in having a better IELTS experience.

\section{General background}

\subsection{The IELTS speaking test}

IELTS is considered one of the world's most popular English language tests. This test is designed to evaluate the language proficiency of individuals who are planning to work or study in countries where English is deemed as a main communicative language (IELTS British Council 2017). IELTS is recognised, nowadays, as a prerequisite for all English-medium majors in higher education. For instance, Hamdan and Abu Hatab (2009: 394) posited that the degree of one's knowledge of English in Jordan in general and Amman, the capital, in particular 
can be viewed as necessary, since the majority of job advertisements require a good command of English. Annually, more than two million IELTS tests are taken around the world (IELTS British Council 2017). As a language proficiency test, IELTS is designed to test all four language skills mentioned in section 1. According to Taylor (2001), IELTS is employed to evaluate both academic and general levels of English proficiency. The speaking skill is assessed through a face-to-face interactive interview on various topics with a native-speaker of English. The interview lasts for 11-15 minutes and is recorded on tape for evaluation purposes. The IELTS speaking test is divided into three parts (Karim and Naushaba 2014: 152):

- Part 1: includes an introduction conducted in a series of short questions designed to make the candidate comfortable and, in a way, to break the ice. The examiner asks the examinees simple questions related to the latter's life, home, work, family, country, study interests, etc. For instance, the examiner may ask the following questions: "what are the most popular dishes in your country?" or "why did you decide to study law?"

- Part 2: in which the candidate has to speak about a selected topic (in a form of monologue) for 2-3 minutes. The topics are usually general in nature, e.g. a movie, activity, life event, etc.

- Part 3: consists of a dialogue between the examiner and the examinee on a topic related thematically to the one in part 2 .

Brown (2000) explained that the reason for using an oral interview in the IELTS test is that it provides a good setting for the examiner to test the communicative and interactional skills of the examinees, imitating a real-life interaction. A wide range of skills are assessed during the IELTS speaking test, including: (1) the ability to express one's opinion and communicate information on day-to-day topics; (2) the ability to speak at length on a topic using suitable language; (3) the ability to organise one's ideas; and (4) the ability to discuss and speculate about various issues. This study takes a closer look at the speaking test included in the IELTS exam when taken by Arab EFL learners in the UAE context. The next section provides an overview of communication accommodation.

\subsection{Communication accommodation}

It is well known that speakers have the tendency to adapt their speech, in various ways, in response to the dialects spoken by their interlocutors, especially in the context of contact between dialects. That is, speakers may change their rate of use of certain phonetic variants either to make their frequency of use of such phonetic variants similar to that of their interlocutors or do the exact opposite, i.e. to increase the difference between them. This phenomenon is referred to as communication accommodation (Giles 1984, 2007; Coupland and Giles 1988; Auer and Hinskens 2005; Gallois and Giles 2015). In line with communication accommodation theory, these changes produced by speakers can be regarded as 
showing the speakers' desire to converge to or diverge from their interlocutors either to attempt to gain the interlocutor's approval or, conversely, to show social distance, respectively (Trudgill 1986). Thus, this theory is concerned with two primary accommodation processes, namely, convergence and divergence. The former refers to strategies used by speakers in order to adapt to the communicative behaviour of the interlocutor in order to limit social difference. On the other hand, the latter is concerned with actions or behaviour patterns exhibited by speakers to accentuate both verbal and non-verbal differences between themselves and their interlocutors (Giles 2007).It should be noted here that in some cases when speakers attempt to converge to their interlocutor's speech patterns, they end up over-accommodating. Even though their intensions in doing so are good, their convergence can be viewed as condescending (Giles 2007). Hence, it can be seen why this theory is concerned with associations between language, context as well as identity (Gallois and Giles 2015). Due to the fact that the current study focuses on the effect of the IELTS examiner's gender and culture on the performance of Arab IELTS examinees in the speaking test, referring to communication accommodation theory is rather important. The next section reviews some studies that assessed the IELTS speaking test.

\subsection{Cultural awareness of the target language}

It is evident that there is an indivisible bond between language and culture; such a bond can create some difficulties in communicating with speakers of other languages, especially if interlocutors are unaware of certain aspects of the culture of the other (see Alptekin 2002; Clarke et al. 2009; Zibin and Altakhaineh, 2014). For this reason, some researchers (e.g. Wildner-Bassett 1994; McDevitt 2004) argued that being aware of and understanding the culture that is associated with the target language can be regarded as a must for learners of such language. According to Moran et al. (2011), the concept of culture can be defined as rules of social behaviour followed by individuals who belong to the same group. This suggests that the way people behave and interact with each other in different social situations vary relying on their culture. Ilter and Guzeller (2005) proposed that 'culture' can also be used to describe the belief system adopted by a specific society, indicating that such values and beliefs are considered an essential part of the definition of culture. It can be argued, here, that culture in fact conditions the way people are expected to behave, as such being aware of the culture of the other may control the way one interacts with that individual. Similarly, lack of awareness of the culture of the interlocutor can cause misunderstandings and even communication breakdowns. Taking into account that the social patterns are different from one culture to another, Ariffin (2006) suggested that various responses are produced by individuals who do not belong to the same culture; such responses could either be positive, negative or neutral. Drawing on the above, it is assumed that the way people behave towards other cultures can have an impact on the attitudes of those people and their linguistic behaviour, taking into consideration that they may not know certain aspects of the culture of the other. These assumptions are investigated in the current study to determine 
whether the culture and the gender of the IELTS examiners can influence the performance of Arab EFL learners on the IELTS speaking test.

\subsection{Studies tackling the assessment of the IELTS speaking test}

Reviewing the relevant literature on assessing the IELTS speaking test, it appears that only few studies have tackled this subject (e.g. O'Loughlin 2000, 2002; Khan, 2006; Roshan, 2013; Karim and Haq, 2014 among others). In a rather relevant study, O'Loughlin (2000) examined the effect of gender on the IELTS oral interview on two levels, i.e. its effect on the discourse of the interview and its impact on the rating process. O'Loughlin (2000) speculated that differences between male and female communicative styles could be reflected in the discourse of the interviews in the IELTS oral interview. In addition, this effect can arise in response to the examiner's gender as well. His study was based on interviews with 16 candidates divided equally into 8 females and 8 males, who were each examined by a female and a male examiner. The interviews were recorded, transcribed and analysed. The results revealed that there were some gender differences between the male and female examiners and candidates, yet these differences did not yield a consistent gender pattern. That is, the majority of examiners and candidates followed a collaborative and supportive speech style regardless of their own gender or that of their examiner. Therefore, O'Loughlin (2000) concluded that gender does not have a significance effect on the IELTS speaking test. O'Loughlin's (2000) study was the first systematic one to tackle this issue. O'Loughlin (2000) only interviewed the candidates themselves but did not interview their teachers to explore their point of view. Even though O'Loughlin (2000) investigated the effect of gender on the IELTS oral interview, the candidates were mostly Asian, e.g. Chinese, Indonesian, Japanese, Korean and Thai. The current study, however, investigates the effect of the IELTS examiner's gender and culture on the performance of Arab IELTS candidates. One may argue, here, that the whole situation could yield different results when taking into account the gender and culture of both the examiners and examinees. One's behaviour and upbringing is greatly influenced by culture; thus, the behaviour of Arab male and female IELTS candidates may differ from that of Asian IELTS candidates, which provides a solid rationale for this study.

In another study, Khan (2006) examined whether the IELTS speaking test may exhibit subtle cultural biases in terms of its structure, vocabulary patterns and methodology. The aim of Khan's study was to draw the attention of IELTS designers to some of these issues and to provide feedback from a local context. Using questionnaires followed by focus group interviews of sixteen IELTS examiners in Bangladesh, the results reveal that cultural bias has a strong presence in the topics discussed in the IELTS speaking test in the Bangladeshi context. Specifically, cultural bias was evident in the vocabulary and question patterns of the speaking test. For example, Khan (2006) indicated that it was rather challenging for Bangladeshi IELTS candidates to respond to words such as souvenir and holiday due to the fact that these words do not exist in their cultural repertoire. This can be attributed to the fact that tourism is not that common in 
Bangladesh, a country with limited financial resources. Therefore, the IELTS examinees in Bangladesh lack the correct terminology to describe such activities. Khan (2006) argued that the presence of culturally unfamiliar features can negatively impact on the examinees' oral performance. Khan's study (2006) focused on cultural bias but not on the effect of the gender of the IELTS examiner; the current study seeks to further investigate the effect of both the culture and gender of IELTS examiners on the performance of Arab examines on the IELTS speaking test.

Reviewing the literature demonstrates that some studies aimed to evaluate the design of language proficiency tests, e.g. the IELTS and analyse the criteria that were relied on to assess the candidates. For instance, Brown (2003) investigated the ways interviewers elicit demonstrations that reflect the communicative ability of the candidates and how their methods of elicitation influence the IELTS candidate's performance and in turn the raters' understanding and evaluation of the candidate ability. The results showed that the interviewer is intimately implicated in evaluating the oral proficiency of the candidate. The results also demonstrated that the two interviewers used different techniques, topics and provided different feedback. As a result, it was argued based on the verbal reports supplied by some raters that such differences yielded different impressions of the candidate oral ability. Brown (2003) argued that the results may reflect a lack of standardisation across interviews in the speaking component of language proficiency tests and thus potential unfairness.

Karim and Naushaba (2014) examined the IELTS oral interview, focusing on both its strengths and weaknesses. The two researchers adopted Hughes' (2003) criteria for assessing oral ability in their data analysis. Hughes' (2003) criteria focused on setting a suitable task to generate a representative sample of the population under investigation and on ensuring the reliability and validity of the selected sample as well as its scoring. Following data analysis and application of Hughes' criteria to the IELTS speaking test, Karim and Naushaba (2014) suggested certain possible measures for improving the IELTS speaking test and increasing its validity and reliability. One of the most important conclusions arrived at in their study is exerting all efforts to avoid subjectivity and bias in the IELTS speaking test. In particular, the two researchers recommended that there should be more than one examiner in the IELTS oral interview. Their rationale behind this suggestion is that it increases the reliability of the test through eliminating the chance of the examiner's bias. As a result, the assessment may become more objective. The two researchers' work was more like a descriptive and evaluative study rather than an experimental one which examines the opinions of human participants. The current study is an experimental one aiming to investigate the opinions and experiences of Arab IELTS examines who took the IELTS speaking test. However, the recommendations made by Karim and Naushaba (2014) could be relevant to the current study and will be further discussed in section 4.3.In another recent study, which followed an experimental approach to evaluating English language proficiency tests, Hamdan and AlHawamdeh (2018) investigated the extent to which 'face', namely, audio visual 
dialogues, influences the listening comprehension of advanced Jordanian EFL learners in a test resembling the TOFEL in comparison to its absence in other tests such as the academic IELTS. The results revealed that including visuals improves the performance of participants in listening tests. Given the importance of such tests for the purposes of study and work in western English-speaking countries, as noted by Hamdan and Al-Hawamdeh (2018), including visuals can be deemed necessary. Following the same line of reasoning, this study argues that concerns regarding the effect of the gender and culture of the IELTS examiner on the examinees' performance need to be taken into account in designing the questions in the IELTS speaking test and by extension other language proficiency tests.

Drawing on the above literature, it appears that investigating the effect of the gender and culture of the IELTS examiner on the performance of IELTS examinees on the oral interview has not been given due attention, especially if one takes into account the importance of the IELTS exam for obtaining a degree in higher education or a job in an English speaking country. It can also be noted that this issue has not been discussed in an Arabic-speaking country. Thus, this study aims to bridge this gap by providing answers to the following research questions:

1) Based on the viewpoints of 30 IELTS Emirati examinees and 10 IELTS teachers, how does the gender of the IELTS examiners of the IELTS speaking test affect the answers of the Arab examinees in the UAE context?

2) Based on the viewpoints of 30 IELTS Emirati examinees and 10 IELTS teachers, how does the culture related to the English language affect the answers of the Arab examinees in the UAE context?

The following section provides a description of the methodology adopted in this study to elicit data.

\section{Methodology}

\subsection{Sample}

Two groups of participants took part in the current study. The first group included 30 IELTS examinees who took the IELTS test at Al-Mukhtar Centre in Al Ain (Abu Dhabi), the UAE. This centre is approved as a test venue by the British Council. The participants included 15 females and 15 males who have taken the IELTS test two days before this study was conducted. This was done to ensure that the participants remembered their answers and experience during the IELTS speaking test. In addition, all these participants were Emirati citizens living in $\mathrm{Al}$ Ain (Abu Dhabi).This was done to obtain a sample representative of the Emirati culture and thus validate any results we obtain. These participants studied English at school and university. Their native language is Emirati Spoken Arabic (ESA) and they speak English as a foreign language with different proficiency levels based on their own evaluation. Their mean age was 34 years old. Due to their age, the participants could be described as aware of many aspects related to the target culture but many of them mentioned that they had not had the chance to 
communicate with native speakers of English on a regular basis. Regardless of their level of exposure, it should be observed that such exposure can be regarded as a limitation of the current study. All of the candidates took preparatory IELTS courses before taking the IELTS exam, which means that they were familiar with the test design. These participants were accessed through Al-Mukhtar Centre. The method of sampling we used was stratified sampling, whereby the entire population (Emirati candidates who took the IELTS test at Al-Mukhtar Centre) was divided into groups, then a simple random sampling was used to select the participants from the different groups insuring randomness of selection (Frankfort-Nachmias and Nachmias 2007). The second group consisted of nonnative 10 IELTS teachers who work in IELTS teaching centres in Al Ain (Abu Dhabi), the UAE. Their nationalities were Jordanian, Syrian, Palestinian or Egyptian. Their IELTS teaching experience inside the UAE ranged between 5-10 years. These ten participants included 6 males and 4 females. This group was recruited through Al-Mukhtar Centre and through personal contact. A list of 60 IELTS teachers was obtained and they were contacted randomly to be asked about their willingness to take part in this study. Eventually, 10 IELTS teachers consented to participate in this study voluntarily and were interviewed inside Al Ain University campus. The reason for including the latter group was to examine their viewpoints regarding the IELTS speaking test and get more insight into their experience as IELTS teachers who interacted with many Arab candidates that took the IELTS test in the UAE. Only non-native participants were selected because through our experience as English teachers and based on the answers supplied by the examinees, it was observed that the majority of Emirati students prefer to take an IELTS preparatory course with non-native teachers because they feel more comfortable asking them questions, especially if they need clarification in their mother tongue. With regard to the IELTS examiners themselves, based on the information supplied by Al-Mukhtar Centre, the IELTS examiners were either British or Australian and their mean age is 47 years old. There were also both male and female examiners who were selected based on their working schedule since they work in more than one centre that gives the IELTS exam. Most of the examiners who work at Al-Mukhtar Centre have been working there for more than 1 year.

\subsection{Data elicitation tools}

Two qualitative data elicitation tools, namely, interviews and focus group discussions were adopted to obtain information from the participants who took part in this study. The reason for not employing a quantitative data elicitation tool was because the type of data the researchers were interested in and which may provide potential answers to the research questions can only be elicited through qualitative data elicitation tools (see O'Loughlin 2000, 2002; Curtis et al. 2014). It was suggested by Bernard (2011) that one of the most effective methods to obtain in-depth information related to the topic under investigation is through prompts and probes, such technique can be used in interviews and focus group discussions enabling researchers to extract more insightful information from the participants. 
In addition, Bryman (2004) explained that interviews and focus group discussions enable researchers to get non-verbal data which can be regarded as crucial because they reveal the participants' feelings about the topic being investigated. In addition, it can be an indication of honesty or doubt in relation to the information the participant is providing. The nature of the current study may not require a data elicitation tool that yields statistical data because the number of participants is not large, and the type of data required to provide answers to the research questions is qualitative rather than qualitative. Thus, semi-structured interviews were conducted with the first group of participants, namely, the 30 IELTS examinees. The reason for choosing semi-structured interviews, rather than structured or unstructured ones is that semi-structured interviews combine the strengths of both structured and unstructured interviews, enabling the researcher to obtain a better understanding of the participants' viewpoints and attitudes on the topic under investigation (Rabionet 2011; Quinn Patton 2015). The participants were interviewed individually for approximately 30-40 minutes and were asked questions related to their experience of taking the IELTS speaking test. The questions were focused on the nature of topics discussed during the IELTS speaking test in terms of themes and cultural specificity (see section 4.1).

With regard to the second group, semi-structured focus-group interviews were conducted with the IELTS teachers. To facilitate the discussion, this group was divided into two sub-groups; the first one included 2 males and 2 females, while the second group consisted of 2 females and 4 males. According to Denscombe (2010), semi-structured focus-group interviews are effective data elicitation tools, since they are flexible and they enable the researcher to reduce his/her control over the discussion; thus, providing more information from the participants. Since the IELTS examinees take preparatory IELTS courses before they take the IELTS test, exploring the viewpoint of the teachers who give them these preparatory IELTS courses can provide more insights into the examinees experience with regard to the IELTS speaking test. During these focus-group discussions, the researchers asked the participants about their experience in teaching the IELTS speaking component and their viewpoints on the IELTS speaking test. Our discussion was focused on what the examinees thought of the topics included in the IELTS test and on the way the examinees interacted with the examiners, taking into account the IELTS examiner's gender and culture. Each interview with each group lasted for approximately 1 hour. The interviews with both groups were tape-recorded, transcribed and then analysed to provide answers to the research questions. The next section presents the results and discusses them.

\section{Results and discussion}

This section presents and discusses the answers provided by the IELTS examinees on the semi-structured interviews and those provided by the IELTS teachers on the semi-structured focus group discussions. This section is subdivided into three subsections: the first one discusses the answers obtained from the 30 IELTS examinees on the semi-structure interviews. The second one discusses the answers 
provided by the 10 IELTS teachers on the semi-structured focus-group discussions. Finally, the third section provides answers to the research questions based on the previous two sections and provides some implications that can be drawn from the discussion.

\subsection{Data analysis of the answers provided by the 30 IELTS examinees}

Starting with the examinees' answers on the semi-structured interviews, the researchers' questions were focused on the following aspects:

1) Whether the gender of the IELTS examiner had had any impact on their answers on the IELTS speaking test.

2) Whether the speech style of the IELTS examiner had had any effect on their language and speech style on the IELTS speaking test.

3) Whether the topics they discussed in parts 2 and 3 of the IELTS speaking test were challenging in terms of theme and culture specificity and appropriateness.

4) Whether the examinees' choice of the topics in part 2 in the IELTS speaking test was affected by their local culture and beliefs.

With respect to the first aspect, the answers provided differed based on the gender of the examinee. For instance, out of the 15 female examinees who were interviewed, 10 indicated that the gender of the IELTS examiner plays a role depending on the individual being examined (cf. O'Loughlin 2000, 2002). They explained that the Emirati society was more conservative in the past and that interaction between both genders was discouraged and even banned in some contexts. However, in recent times, communication between both genders is regarded as relatively normal and individuals have started to expect it in daily-life activities. The following is a quotation from a female examinee translated into English:

(1) Due to our traditions which classify us as a conservative society, the gender of the IELTS examiner may have really mattered twenty or thirty years ago. Women were looked down upon if they communicated with strange men because it is "shameful", but now things are a bit different. At the beginning, I was nervous because my examiner was a male, but then everything was OK. What really mattered was whether I can answer the questions he asked and whether I demonstrated the necessary speaking skills.

The five other female examinees, two of whom wore a veil that covered their face, stated that they would prefer a female examiner because they felt shy and embarrassed talking to a male examiner whom they have met for the first time. They explained that their nervousness affected their answers in a negative way and they believed that if the examiner had been a female, their oral performance 
would have been better. With regard to the 15 male examinees who were interviewed, 14 participants indicated that they prefer a female examiner, rather than a male. When asked about the reason, many of them explained that it is easier for them to communicate with a female rather than a male, especially if they make mistakes on the test. They indicated that female examiners are more supportive and easier to communicate with.

When asked whether the examiner's speech style affected their answers, i.e. whether they felt the need to imitate the examiner's speech style, 13 females and 12 males explained that it did not. Many females stated that it was important for them to listen carefully to the examiner's words in order to understand them correctly and, in turn, provide an accurate answer. However, they did not try to imitate the way she/he spoke, because they believed that as long as their English is understandable and they are able to communicate effectively with their interlocutors, they do not have to imitate the accent or the speech style of the examiner. Below is a quote provided by a female participant translated into English:

(2) Imitating the accent of the examiner is not smart, because we need to accept the fact that we are not native speakers of English. It is like wearing clothes that do not fit you and trying to convince people that they look good on you.

Twelve male participants provided similar answers, saying that one should be proud of who he is and how he speaks. One of the participants even indicated that "people should be proud of what makes them unique". Two males, however, disagreed. Below is a quotation supplied by a male participant:

(3) Being able to speak like a native speaker of English is good because this means that you are fluent. This does not mean that you are not proud of your nationality and your language.

Based on communication accommodation theory discussed in section 2.2, it seems that both female and male participants have a tendency to diverge from rather than converge to the speech style of the interlocutor (see Giles 2007). That is, their actions or behaviour patterns are intended to accentuate verbal differences between themselves and their examiners, establishing social distance. Given that the IELTS test paves the way for future careers, education, or even life in Englishspeaking countries, it appears that expressing their identity and uniqueness is more important to Emirati IELTS examinees (see Trudgill 1986). Their answers demonstrated their pride of their "foreignness" rather than the opposite.

Concerning the third and fourth aspects pertaining to the topics discussed in the IELTS speaking test and whether they were difficult to discuss in terms of theme and culture appropriateness, the participants stated that certain topics were difficult to discuss. For instance, a male participant indicated that he was asked a question about a piece of art he likes. He stated that it was difficult to talk about 
pieces of art because they are not that common where he lives. He also explained that the first thing that came to his mind is a painting and that he has never seen a painting drawn by someone famous in his entire life and he would not be even interested in them. Such a topic, according to the participant, is more related to the examiner's culture rather than his culture. The participant also stated that it would have been more effective if the examiner asked him about something which is common in the UAE; this would have given him the chance to express his opinion and engage in a conversation with the examiner. In a similar view, a female participant stated that her question in the IELTS speaking test was about the type of music she likes. Even though the candidates are aware of the fact that they have a choice of choosing not to answer a question if they feel uncomfortable about the topic, most of them indicated that they avoid doing that because they feel that it may affect their mark. Below is a quotation that explains her point of view:

(4) When I was asked about the type of music I liked, I had the impression that I should be familiar with different types of music and then I should explain the type that I like. Since I only listen to Arabic songs, I did not know whether my answer was correct or not because I did not know how to explain that I like words in Arabic songs since they touch my heart, but I did not know what type of music it was. It made me feel bad because I thought what if I do not listen to any songs? How could I have answered the examiner's question? Some of my friends are very religious and they do not like music.

The participant's answer may indicate that she found the topic discussed in her IELTS speaking test rather challenging. Another female participant was asked about a place with animals, she was asked why she thought such a place is an interesting place to visit. The participant indicated that she has never been to a zoo because she does not find it an interesting place. She explained that her answer may not have been to the examiner's liking even though he tried to hide it. She explained that it could be the case that from where the examiner comes, animals and pets are rather important and interesting, but that is not always the case in the UAE based on the participant's response. It should be noted here that having pets is quite common in the Arab culture but it differs from one place to another.

It is worth pointing out that some participants both male and female indicated that in certain topics they felt that using some Arabic proverbs could have made their point clearer (see Zibin and Altakhaineh 2014on more detail on Arabic proverbs), but they were afraid that they may not be able to explain them to the examiner who may find the proverb strange or irrelevant. For example, when asked to describe a person whom the participant would go to when he is facing a difficult situation, one male participant stated that he wanted to say that he would go to someone whom he can trust and that everyone should have such a person using the following proverb: dme:t?akalni: ssamakyfe:t?akalni:tte: ${ }^{6}$ when 
I bled, the fish ate me and when I fell asleep, the birds ate me'. This proverb roughly means that when a person has nobody whom he can trust and rely on, then he/she would always be in danger. The participant explained that he was not able to convey this proverb even though it fit perfectly in the discussion. Here, it can be suggested that the participants encountered a language barrier in the IELTS oral interview because of their culture although one can suggest here that being unable to find an L2 equivalent to a native proverb could be related to the degree of proficiency rather than culture. Some participants also struggled sometimes to find the correct vocabulary that conveys their opinion without being impolite or offensive (see Altakhaineh and Rahrouh 2015). These results are similar to those of Khan (2006), who argued that some topics discussed by the IELTS examiners were either irrelevant to the Bangladeshi participants or that these participants struggled to find the appropriate vocabulary, making it difficult for them to be active during the oral interview. However, it should be pointed out that other female and male participants found the topics discussed in their IELTS speaking test rather interesting and relevant to their interests. For instance, a male participant was asked about his favourite shop and he thought that this topic gives one the chance to talk more and demonstrate his English speaking skills. Discussion of these results are provided in section 4.3.

\subsection{Data analysis of the answers provided by the 10 IELTS teachers}

To get more insight into the impact of the gender and culture of the IELTS examiner on the oral performance of the Arab examinees on the IELTS speaking test, we move on to discuss the answers provided by the 10 IELTS teachers who teach IELTS preparatory courses during the semi-structured focus group discussions. These teachers were asked questions which focused on the four aspects mentioned previously. With respect to the gender of the IELTS examiner, the teachers thought that given that the Emirati culture is conservative to some extent, based on their experience, they believe that the gender of the examiners will most likely affect the behaviour of female examinees, since many of them would feel shy talking to a male. Below is a quotation provided by a female IELTS teacher:

(5) I had a female in my class once who asked me whether the interviewer in the IELTS oral interviewer would be male or female. When I told her that they could be either, she was in distress. I followed up with her after class and she told me that she would prefer a female interviewer because she would feel "more relaxed" talking with a female rather than a male.

Other teachers (both male and female) stated that male examinees prefer to have a female examiner rather than a male because it would be easier for them to communicate with the opposite sex. The teachers elaborated that based on their experience and their knowledge of the Emirati culture, men usually feel ashamed 
when they make a mistake in front of a male and that it would be easier to make a mistake in front of a female examiner. These views supplied by the IELTS teachers lend more support to the results generated from the IELTS examinees' interviews, indicating that the gender of the IELTS examiner can have an impact on the performance of Arab examinees on the IELTS speaking test. Another observation can be detected here, namely, it is clear that culture can have an impact on the way both genders behave in certain situations (see Altakhaineh and Zibin 2014).

In relation to the third and fourth aspects pertaining to the culture of the IELTS examiner, the semi-structured focus group discussions with the IELTS teachers show that the topics chosen by the IELTS examiners in the second and third parts of the speaking test should take into account the cultural context of the examinees, providing topics for discussion accordingly. The teachers also indicated that many of the IELTS candidates they taught have not had enough exposure to the target culture and that, according to them, may result in lack of awareness of certain cultural aspects of the target culture causing some difficulties in communication. They also explained that some IELTS candidates they taught felt the need to memorise some answers related to topics they find difficult to discuss because they are not that relevant to the UAE context, such as art. Below is a quote provided by an IELTS teacher during the focus group discussion:

(6) A male participant told me that in a previous attempt to take the IELTS exam, the examiner asked him about when people in his country wear traditional clothing. He explained that he may not have understood the question because in the UAE the majority of men wear kandura, which is an ankle-length white shirt, whereas many women wear an abaya, a black garment covering most parts of the body. The participant indicated that he felt that the examiner was not aware of the culture in the UAE. Otherwise, he may not have asked this question.

The answer provided by the IELTS examinee may show that he thinks that some IELTS examiners may not be aware of the culture of the local community to which the examinee belongs. The above quotation reflects his point of view. Even though the question of the IELTS examiner may be interpreted in another way, where traditional clothing can be interpreted as traditional ceremonial clothing that are only worn on traditional occasions such as national Eids and ceremonies. The following section discusses these results and provides answer to the two research questions.

\subsection{Discussion and implications}

With regard to the first research question which is concerned with the effect of the gender of the IELTS examiner on the performance of the Arab IELTS examinees on the IELTS speaking test, the responses provided by the participants showed 
that the gender of the IELTS examiner can have an impact on the linguistic behaviour of the participants and their performance on the IELTS speaking test. It can cause them to hesitate, to feel embarrassed or uncomfortable which may affect their answers on the test. Contrary to O'Loughlin's $(2000,2002)$ findings, the results provided in the current study showed that the gender of the examiner does have an effect on the participants' answers on the IELTS speaking test. Both genders explained that the gender of the examiner is important as far as their oral performance on the IELTS speaking test is concerned.

With respect to the second research question which is concerned with whether the culture related to the English language affects the answers of the Arab examinees in the UAE context, the responses provided by the participants demonstrated that despite the participants' awareness of the target culture given their age and the fact that they studied English at school and university, the target culture has possibly affected their answers on the IELTS speaking test. Such an effect could be related to their inability to answer the question or to elaborate on it. It could have also yielded confusion or lack of understanding based on the answers provided by the examinees. According Chastain (1971), several ESL/EFL learners may not view the native speakers of the target language as real individuals because they may not interact with them a lot or because the examples they study at school or university which are found in textbooks seem to be unreal to L2 learners. Furthermore, the majority of candidates are exposed to the target culture through the media and movies which may not help them interact with native speakers of English. This argument may be regarded as plausible in the context of this study, since the responses provided by the participants show that some IELTS examinees indicated that some topics discussed in the IELTS speaking test were not culturally suitable to the Emirati culture, which affected their answers on the speaking test (see quote 4). Based on these results, it can be suggested that the different cultures of the interlocutors can have an impact on their attitudes and oral linguistic behaviour (see Ariffin 2006). In fact, as far as communication accommodation is concerned, the tendency of Emirati examinees to diverge from the speech style of the IELTS examiner may reflect another effect of the culture on the linguistic behaviour of individuals, i.e. the Emirati participants' pride of their language and culture and lack of desire to imitate the linguistic behaviour of individuals of the target culture. Based on the above discussion, it appears that the culture of the IELTS examiner can have an impact on the oral performance of Emirati IELTS examinees in terms of relevance and culture. It also appears the culture of the examinee can also have an impact on his/her answer on the test.

Drawing on the above discussion, a number of implications and suggestions can be recommended that aim to enhance the IELTS experience in the UAE context. Firstly, it is suggested that the topics selected in part 2 in the IELTS speaking test should be compatible with the local culture of the country. This needs to be done in order to give the examinees the opportunity to effectively discuss their opinions with the examiners on culturally-relevant topics. This can be considered as part of the standardisation process of the IELTS test as 
recommended by Brown (2003) to ensure fairness in marking. Because if the examinees are asked questions that are not in line with their local culture or are unfamiliar to them (see Khan 2006), their answers may not accurately reflect their English oral proficiency. It is recommended that the topics included in parts 2 and 3 of the IELTS speaking test should not be culture specific to the UK and Australian context; conversely, they should accommodate the culture of the candidate. Secondly, in relation to the gender of the IELTS examiner, it can be recommended that IELTS teachers should draw candidates' attention to the fact that the examiner could be either a male or a female; thus, they should be prepared to talk with both. It can also be recommended that the British council centre may wish to consider adding a section mentioning the candidates' preference of the gender of the examiners and attempt to allocate candidates based on their choice. In addition, in order to avoid any bias, it was recommended by Karim and Naushaba (2014) that more than one examiner should be included in the IELTS speaking test. We might add that if such recommendation is taken into account, then the two examiners should be of different sexes, and at least one of them should be acquainted with the local culture of the candidates. Finally, it can be suggested that $\mathrm{L} 2$ curriculum designers and teachers may wish to integrate tasks, activities and exercises that train L2 learners to use real-life expressions in the target language in order to improve their L2 lexical intercultural proficiency.

\section{Conclusion and recommendations}

This study has investigated the impact of the gender and culture of the IELTS examiner on the performance of Arab examinees on the IELTS speaking test in the United Arab Emirates (UAE) context, especially in Al Ain (Abu Dhabi). The data has been elicited through two qualitative data elicitation tools via semistructured interviews with both female and male IELTS examinees in Al Ain (Abu Dhabi) and semi-structured focus group interviews with 10 IELTS teachers. Based on the responses provided by the two groups of participants, the results have shown that the gender of the IELTS examiner can influence the performance of the Arab examinees on the IELTS speaking test. However, in terms of communication accommodation, the answers provided by the IELTS examinees exhibit a divergence tendency rather than a convergence one, indicating a desire to establish social distance with the interlocutor, which may reflect their strong feelings about their culture and identity. The results have also demonstrated that the culture of the examiners influenced the answers provided by the examinees, who were not aware of certain cultural aspects related to the questions asked in the IELTS speaking test and vice versa. Several reasons were suggested to account for the linguistic behaviour of the IELTS examinees on the speaking test. For instance, it has been argued that the conservative Emirati culture could have played a role in the way Emirati examinees interacted with the IELTS examiner on the IELTS speaking test. The study concluded with some recommendations that aim to enhance the IELTS experience in the UAE. 
International Journal of Arabic-English Studies (IJAES) Vol. 19, No.1, 2019

\section{Acknowledgements}

We would like to thank the three anonymous reviewers for their useful comments on an earlier draft of the paper. Many thanks also go to the editor-in-chief of IJAES, Professor Jihad Hamdan, for his professionalism and cooperation. All remaining errors and inaccuracies are, of course, ours alone.

Abdel Rahman Mitib Altakhaineh (PhD)

Al Ain University of Science and Technology

Al Ain, United Arab Emirates

Khawlah M. AL-Tkhayneh (PhD)

Al Ain University of Science and Technology

Al Ain, United Arab Emirates

Hanan N. Rahrouh (MA)

Al Ain University of Science and Technology

Al Ain, United Arab Emirates 


\section{References}

Alptekin, Cem. (2002). 'Towards intercultural communicative competence in ELT'. ELT Journal, 56(1): 57-64.

Altakhaineh, Abdel Rahman M. and Aseel Zibin. (2014). 'Perception of culturally loaded words by Arab EFL learners'. International Journal of Linguistics, 6 (3): 1-22.

Altakhaineh, Abdel Rahman M. and Rahrouh, Hanan. (2015). 'The use of euphemistic expressions by Arab EFL learners: Evidence from Al Ain University of Science and Technology'. International Journal of English Linguistics, 5(1): 14-21.

Ariffin, Sherene. (2006). 'Culture in EFL teaching: Issues and solutions'. TESL Working Paper Series, 4(1): 75-78.

Auer, Peter and Hinskens, Frans. (2005). 'The role of interpersonal accommodation in a theory of language change'. In Peter Auer, Frans Hinskens and Paul Kerswill (eds.), Dialect Change: Convergence and Divergence in European Languages.335-357. Cambridge, UK: Cambridge University Press.

Basow, Susan. A. (1995). 'Student evaluations of college professors: When gender matters'. Journal of Educational Psychology, 87(4): 656-665.

Bernard, H. Russel. (2011). Research Methods in Anthropology: Qualitative and Quantitative Approaches. New York: Rowman Altamira.

Brown, Annie. (2003). 'Interviewer variation and the co-construction of speaking proficiency'. Language Testing, 20(1): 1-25.

Brown, Annie. , (2000). 'An investigation of the rating process in the IELTS oral interview'. Research Reports, 3: 49-85.

Bryman, Alan. (2004) Social Research Methods. Oxford: $2^{\text {nd }}$ edition. Oxford University Press.

Byram, Michael. (1994). Teaching-and-Learning Language-and-Culture. Bristol: Multilingual Matters.

Chastain, Kenneth. (1971). The Development of Modern Language Skills: Theory to Practice. Chicago: Rand McNally.

Clarke III, Irvine, Theresa B. Flaherty, Newell D. Wright, and Robert M. McMillen. (2009). 'Student intercultural proficiency from study abroad programs'. Journal of Marketing Education, 31(2): 173-181.

Coupland, Nikolas and Giles, Howard (Eds.). (1988). 'Communicative accommodation: Recent developments'. Language and Communication, 8: 175-327.

Curtis, Will, Murphy, Mark and Shields, Sam. (2014) Research and Education: Foundations of Education Studies. London: Routledge.

Denscombe, Martyn. (2010). The Good Research Guide: For Small-Scale Social Research Projects. Maidenhead: Open University Press.

Frankfort-Nachmias, Chava, and David Nachmias. (2007). Study Guide for Research Methods in the Social Sciences. New York: Macmillan. 
Gallois, Cindy and Giles, Howard. (2015). 'Communication accommodation theory'. The International Encyclopedia of Language and Social Interaction. Wiley Online Library.

Giles, Howard. (2007). Communication Accommodation Theory. New Jersey: John Wiley \& Sons, Inc.

Giles, Howard. (ed.). (1984). 'The dynamics of speech accommodation [Special issue]'. International Journal of the Sociology of Language, 46: 1-155.

Hamdan, Jihad and Abu Hatab, Wafa. (2009). 'English in the Jordanian context'. World Englishes, 28(3): 394-405.

Hamdan, Jihad and Rose Fowler Al-Hawamdeh. (2018). 'The effects of 'face' on listening comprehension: Evidence from advanced Jordanian speakers of English'. Journal of Psycholinguistic Research: 1-11.

Hughes, Arthur. (2003). Testing for Language Teachers. Cambridge: Cambridge University Press.

IELTS. (2017). British Council. https://www.britishcouncil.jo/en/exam/ielts. (Retrieved on 19 November, 2017).

İlter, Binnur Genç, and Cem Oktay Güzeller. (2005). 'Cultural problems of Turkish students while learning English as a foreign language'. Modern Language Journal, 89 (2): 456-461.

Ji, Li-Jun, Zhiyong Zhang, and Richard E. Nisbett. (2004). 'Is it culture or is it language? Examination of language effects in cross-cultural research on categorization'. Journal of Personality and Social Psychology, 87 (1): 5765.

Karim, Shahzad, and Naushaba Haq. (2014).'An assessment of IELTS speaking test'. International Journal of Evaluation and Research in Education, 3(3): 152-157.

Khan, Rubina. (2006). 'The IELTS speaking test: Analysing culture bias'. Malaysian Journal of ELT Research, 2(1): 60-79.

McDevitt, Barbra. (2004). 'Negotiating the syllabus: A win-win situation'. ELT Journal, 58 (1): 3-9.

Moran, Robert T., Philip Robert Harris, and Sarah Virgilia Moran. (2011). Managing Cultural Differences: Global Leadership Strategies for CrossCultural Business Success. London: Routledge.

O'Loughlin, Kieran. (2000). 'The impact of gender in the IELTS oral interview'. International English Language Testing System (IELTS) Research Reports 2000, 3: 1-28.

O'Loughlin, Kieran. (2002). 'The impact of gender in oral proficiency testing'. Language Testing, 19(2):169-192.

Quinn Patton, Michael. (2015). Qualitative Research and Evaluation Methods: Integrating Theory and Practice. London: Sage Publications.

Rabionet, Silvia. E. (2011). 'How I learned to design and conduct semistructured interviews: An ongoing and continuous journey'. The Qualitative Report, 16(2): 563-566.

Roshan, Saeed. (2013). 'A critical review of the revised IELTS speaking test'. International Journal of English Language Education, 2(1): 120-127. 
Sun, Shaung. (2007). 'From linguistic knowledge to cultural awareness'. Intercultural Communication Studies, 16 (3): 192-97.

Tarone, Elaine and Yule, George. (1987). 'Communication strategies in EastWest interactions'. In Larry E. Smith (ed.), Discourse Across Cultures: Strategies in World Englishes. 49-65. New York: London: Prentice-Hall.

Taylor, Lynda. (2001). 'Revising the IELTS speaking test: Developments in test format and task design'. Research Notes, 5: 3-5.

Trudgill, Peter. (1986). Dialects in Contact. Oxford, UK: Blackwell.

Wildner-Bassett, Marry E. (1994). 'Intercultural pragmatics and proficiency: 'Polite' noises for cultural appropriateness'. International Review of Applied Linguistics in Language Teaching IRAL, 32(1): 3-18.

Zibin, Aseel and Altakhaineh, Abdel Rahman M. (2014). 'Informativity of Arabic proverbs in context: An insight into Palestinian discourse'. International Journal of Linguistics, 6(1): 67-83.

Zibin, Aseel. (2016). 'On the production of metaphors and metonymies by Jordanian EFL learners: Acquisition and implications'. Topics in Linguistics, 17(2): 41-58. 